\title{
ZONEAMENTO E POTENCIALIDADE DE ELEMENTOS TERRAS RARAS (ETR) DO GRANITO DE ACARI/RN
}

\author{
Costa, P.R.F., LAE-UFRN; Oliveira, B.S.C., UFRN
}

Copyright 2018, SBGf - Sociedade Brasileira de Geofísica

Este texto foi preparado para a apresentação no VIli Simpósio Brasileiro de Geofísica, Silinópolis, 18 a 20 de setembro de 2018. Seu conteúdo foi revisado pelo Comitê Técnico do Vlil SimBGf, mas não necessariamente representa a opinião da SBGf ou de seus associados. É proibida a reprodução total ou parcial deste material para propósitos comerciais sem prévia autorização da SBGf.

\section{Resumo}

Fora realizado neste trabalho um zoneamento de elementos radioativos do batólito Acari por meio de imagens aerogamaespectométricas de alta resolução adquiridas pela CPRM. Este trabalho tem como objetivo ressaltar a importância da integração de dados geofísicos auxiliando na atualização de mapas geológicos. Perante o estudo foi possível destacar áreas anômalas de Tório, cujo elemento apresenta intrínseca relação com os elementos Terras Raras (ETR) e como resultado definiuse zonas anômalas deste elemento radioativo para um possível projeto pioneiro e a posteriori um jazimento de ETR no Rio Grande do Norte.

\section{Introdução}

Baseado no contraste de propriedades físicas presentes nas diversas litologias terrestres, seja esse contraste de susceptibilidade magnética, radioatividade, gravidade, elétrico, propagação de ondas elásticas ou eletromagnéticas, encontra-se a geofísica. E nela para cada propriedade física exequível, ter-se-á um interesse de prospecção distinta (KEAREY; et al., 2009).

Fazendo-se uso dos contrastes radiométricos, o Serviço Geológico Brasileiro (CPRM) realizou aero-expediçõesgeofísicas entre 2004 e 2014 a fim de fomentar a comunidade científica e o setor mineral do país, atraindo assim novos trabalhos e investimentos (SBGF, 2017). Ao fazer uso dos dados aerogamaespectrométricos imageados no Projeto Aerogeofísico 1092 Paraíba - Rio Grande do Norte realizado no ano de 2010, o qual continha a área de interesse desse estudo, foi possível apurar contrastes dos três principais radioisótopos investigados pela radiometria: potássio $\left({ }^{40} \mathrm{~K}\right)$, urânio $\left.{ }^{238} \mathrm{U}\right)$ e tório ( $\left.{ }^{232} \mathrm{Th}\right)$ existentes no pulso magmático de Acari, o qual compreende um dos granitóides brasilianos.

As anomalias radiométricas dão-se, principalmente, pelo decaimento dos radioisótopos ocorridos pela alta instabilidade em condições naturais do próprio núcleo atômico o qual libera energia através da emissão de partículas alfa $(\alpha)$, beta $(\beta)$ e radiação gama $(\gamma)$. Em que destes o que único aerogeofisicamente detectável é a radiação gama (KEAREY; et al., 2009),

Tais anomalias radioativas estão comumente relacionadas a granitos, uma vez que durante o processo de cristalização magmática, os radionuclídeos primordiais incorporam-se na estrutura cristalina de determinados minerais portando os elementos radioativos, sendo a sua acumulação e distribuição majoritariamente dependente dos processos de diferenciação magmática (TEIXEIRA, et al., 2014).

Embora uma caracterização geológica geral seja essencial, é possível adquirir um maior nível de detalhamento aprofundando-se na geofísica. Consoante Urquhart (2006) o estudo aerogamaespectrométrico é uma precisa forma de mapear geofisicamente as unidades geológicas, sem a necessidade de haver contato direto com o meio e abrangendo uma área em larga escala, que no caso do método radiométrico, além de não ser um método invasivo, preserva a boa forma da geodiversidade local. Além disso, as anomalias correlacionam-se à minerais de valor econômico, entretanto, vale ressaltar que como toda radiação, dada uma exposição prolongada e desprotegida, tais áreas radioativas podem provocar doenças tais como leucemia e outras neoplasias (TEIXEIRA, et al., 2014).

O granitoide de estudo chamado de batólito de Acari encontra-se dentro dos limites do Município de Acari, distante aproximadamente $215 \mathrm{~km}$ da capital do Estado do Rio Grande do Norte, precisamente intrudido no Domínio Rio Piranhas Seridó (CAMPOS, 2016), o qual repousa sobre o Complexo Caicó de idade paleoproterozóica (CPRM, 2006).

\section{Metodologia}

O desenvolvimento desta pesquisa ocorreu a partir de um levantamento bibliográfico com o objetivo de obter um conhecimento prévio dos trabalhos executados na região e integrá-los aos mapas existentes da área escolhida.

Os dados aerogamaespectométricos obtidos em sobrevoos espaçados com linhas de $500 \mathrm{~m}$, altura de 100 m, e direção N-S das linhas de voo (SBGF, 2017) foram levantados pelo Serviço Geológico Brasileiro e estão disponíveis para trabalhos científicos no próprio geobank da CPRM.

Quanto ao processamento e elaboração dos mapas foi possível fazer um detalhamento das anomalias radiométricas presentes na área de estudo utilizando o Software ArcGis 10.2.

Inicialmente, foram inseridos os dados supracitados e com eles feito a classificação de forma manual pelo ArcGis por separação de classes e ajuste dos valores para média, média mais um desvio, média mais dois e média mais três desvios. Durante a classificação foram destacados nos mapas as anomalias de isoteores em 
partes por milhão (ppm) dos elementos Tório e Urânio; e para o Potássio, porcentagem (\%). Para todos os mapas as anomalias foram dispostas em curvas as quais representam os isoteores de cada elemento.

Com o auxílio da carta de Currais Novos, atualizada em 2015, e prontamente baixada no site da CPRM, foi possível visualizar o batólito e delimitar a área de interesse em um shapefile de escala 1:170.000.

As curvas de nível selecionadas para o Potássio são de 1 e 5 \% (Figura 2). Já as respectivas curvas para o Urânio foram de $2 \mathrm{ppm}$ e $5 \mathrm{ppm}$, (Figura 3). Enquanto que o Tório, isoteores de 9 e 25 ppm (Figura 4).

Além disso, foi acrescentado um Hillshade da área e inseridos o grid de coordenadas UTM em intervalos de 5000 metros, além de legendas, escalas, título e a direção do Norte ao mapa.

Com o objetivo de selecionar zonas de interesses específicos para prospecção do ETR por meio das anomalias de Tório mais significativas encontradas, foram geradas 4 zonas de interesses (Figura 5).

\section{Resultados}

A interpretação dos dados aerogamaespectrométricos auxiliam na adição de novas informações de unidades litológicas, uma vez que ele tem pouco alcance em profundidade fazendo com que as informações obtidas se limitem a contatos geológicos superficiais e/ou afloramentos de uma determinada formação (RIBEIRO et al., 2014).

É importante salientar que os radioelementos nas rochas ígneas apresentam uma maior concentração dada uma maior quantidade de sílica disponível, ou seja, rochas félsicas possuem um teor mais elevado de radioelementos do que rochas máficas ou ultrabásicas (DICKSON; SCOTT, 1997). E as rochas que apresentam micas, feldspatos e minerais acessórios como o zircão, a apatita e a monazita, contêm teores maiores de tais elementos (SAPUCAIA et al, 2005).

Pelas anomalias do potássio (fig. 2) contidas no batólito é possível notar que o esse elemento constitui quase todo - corpo estudado se compararmos com os dados geológicos da área feita pela CPRM (fig.1). Isto é possível uma vez que as rochas que apresentam maiores teores de potássio são as rochas ígneas félsicas, como os granitoides, isto devido a sua composição rica em elementos como os minerais feldspatos potássicos e também em micas como as biotitas, encontradas e descritas no batólito por Campos (2016), as quais apresentam entre $6,64 \%$ a $7,76 \%$ de $\mathrm{K}$ (RIBEIRO et al., 2014). A área apresentou valores significativos de $6 \%$ na região sudeste o qual comparando com a abundância média de tal elemento na parte superior da crosta é de 2,32\% (RUDNICK; GAO, 2004).

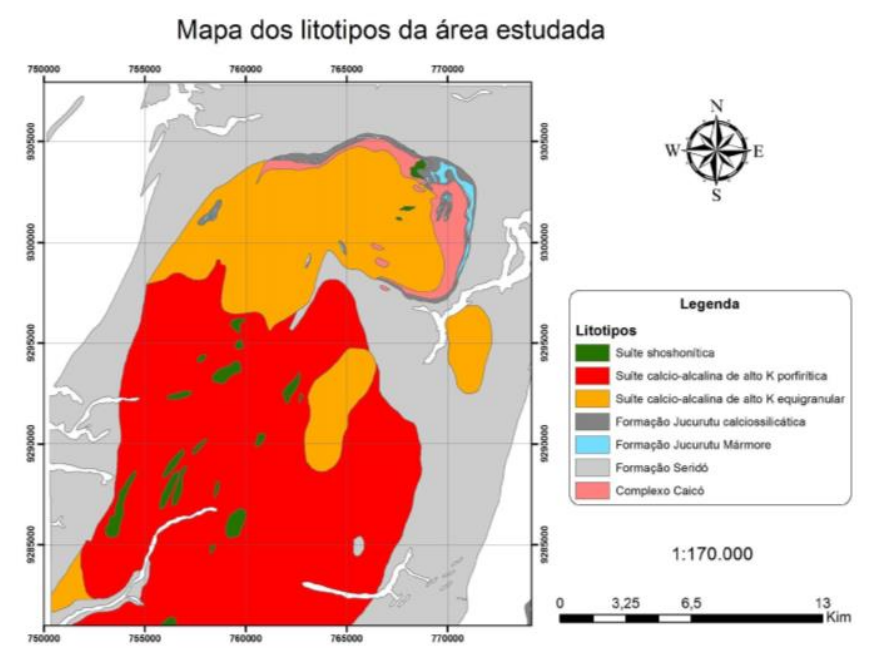

Figura 1: Mod. Nascimento, M.A.L. et al. (2014) das suítes ilustrando os litotipos presentes na área de estudo.

As anomalias do elemento Urânio (fig. 3) para a área estudada, expressam uma difusão em todo o polígono destacado, e com altos teores de concentração no Norte e também sudeste, atingindo valores de até $21 \mathrm{ppm}$ bem mais alto do que a média de $2,7 \mathrm{ppm}$ correspondente às concentrações normais desse elemento na crosta terrestre superior (RUDNICK; GAO, 2004).

As anomalias de Tório (fig.4) encontradas nesse estudo chegam a apresentar valores superiores a $70 \mathrm{ppm}$, e é fácil ver que há um grande contrates desta anomalia com as demais supracitadas, uma vez que dentro da área, as anomalias de Tório concentram-se quase que restritamente dentro do batólito, enquanto que nos entornos dele apresenta valores tão normais quanto as encontradas na natureza que variam em cerca dos 10 ppm (RUDNICK; GAO, 2004).

Segundo Dickson e Scott (1997) o elemento Tório encontra-se presente na composição de minerais como alanita, monazita, xenotímeo e zircão com concentrações que podem atingir valores maiores do que $1000 \mathrm{ppm}$ ou encontrar-se em quantidades-traço nos demais minerais constituintes de rochas.

Os principais minerais que contém Th (monazita e zircão) são ambos encontrados nas descrições petrografias de Campos (2016) para o plúton de Acari e eles são estáveis durante o intemperismo de tal forma que podem acumular-se em depósitos minerais pesados quase que inoxidados.

De acordo com o resultado verificado no mapa (fig. 4) é fácil notar que, uma vez apresentando a menor mobilidade geoquímica e estando contido no plúton pela cristalização de monazita e zircão justifica-se o fato dele não abranger anomalias nas demais litologias do entorno. 

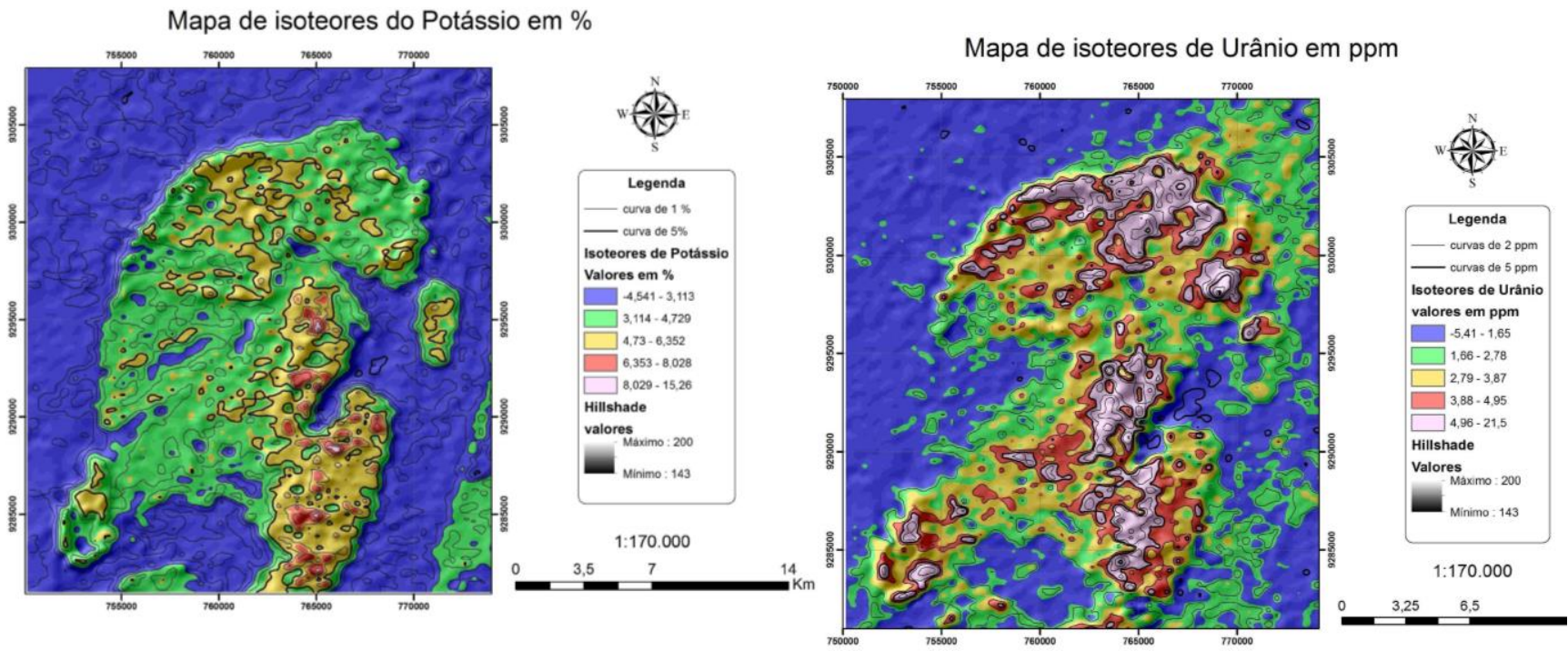

Figura 2: Mapa dos isoteores do elemento Potássio no batólito de Acari/RN.

Figura 3: Mapa dos isoteores do elemento Urânio no batólito de Acari/RN.

\section{Mapas de isoteores de Tório em ppm}

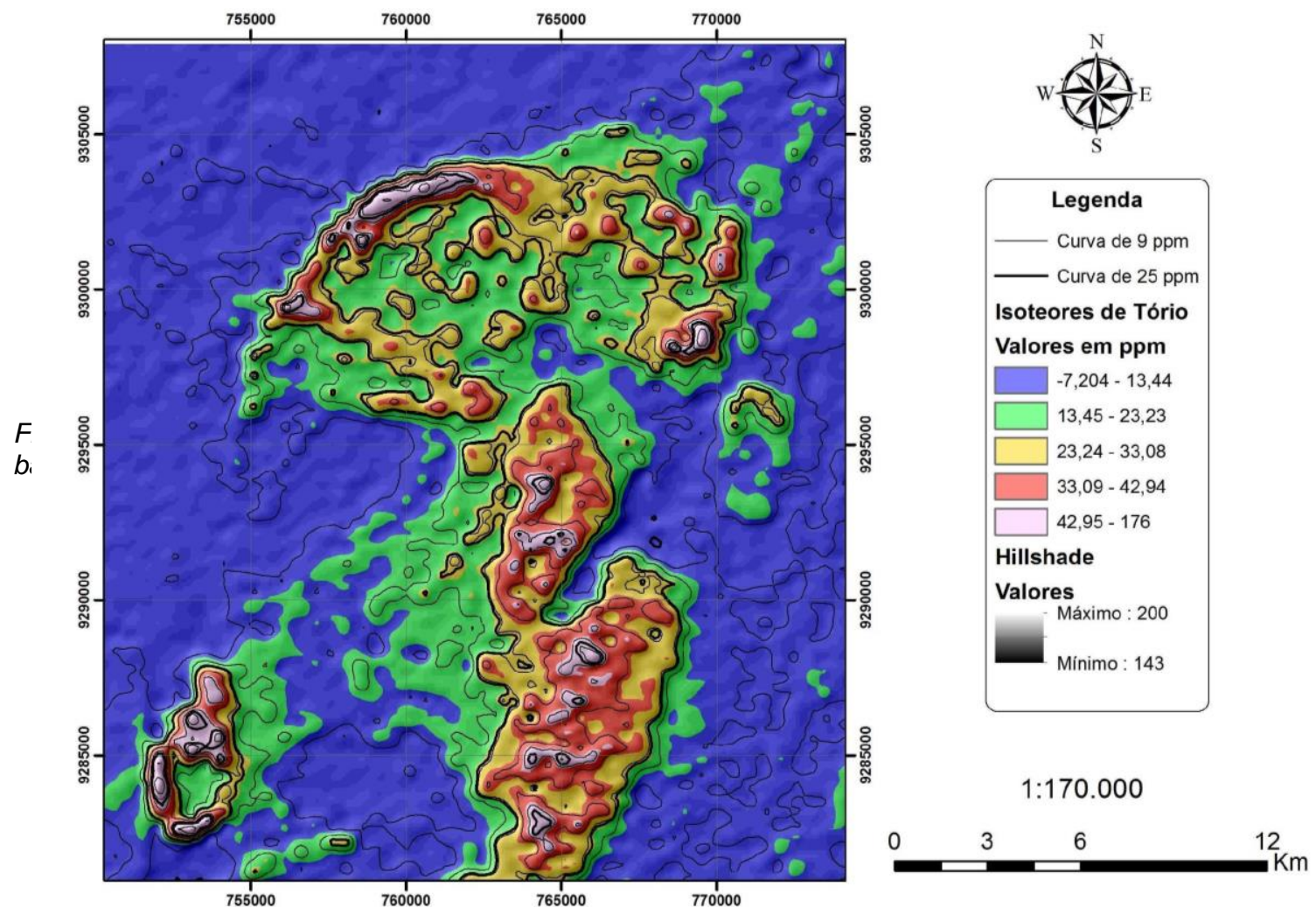

Figura 4: Mapa dos isoteores do elemento Tório no batólito de Acari/RN. 


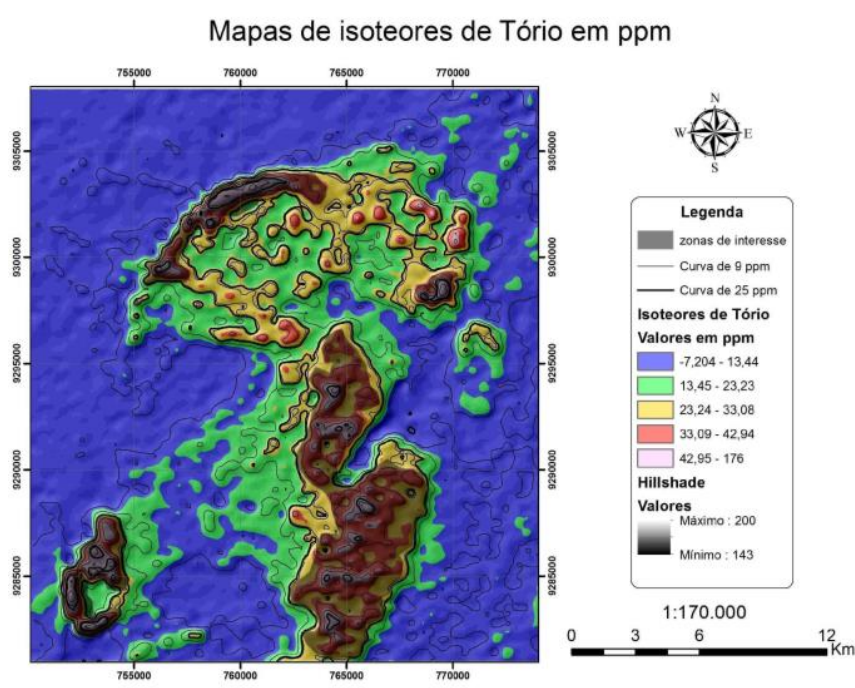

Figura 5: zonas de interesse para isoteores do elemento Tório no batólito de Acari/RN.

O Th durante o intemperismo, pode ser retido em óxidos ou hidróxidos de $\mathrm{Fe}$ e Ti. Além disso tal qual o U, o Th também pode ser transportado e adsorvido em coloides argilosos (DICKSON; SCOTT,1997).

\section{Discussão e Conclusões}

Com as novas informações trazidas por este trabalho, é possível verificar que há grande potencialidade da área para se prospectar ETR. Sugerimos um estudo mais apurado nas quatro regiões com maiores concentrações de Tório ressaltados a fim de gerar maior conhecimento sobre a relação do corpo com quantidades significativas de ETR para um possível projeto e posteriormente um jazimento de tais elementos no Rio Grande do Norte.

Foi observado que a subdivisão geoquímica do maciço de Acari ainda precisa passar por revisões, embora do ponto de vista textural possa compreender a mesma litologia, contudo fica nítido pelos mapas geofísicos a diferenciação química.

Podemos verificar também com base nas anomalias, que embora sejam descritos a presença dos minerais como monazita e zircão (ambos constituídos de $U$ e Th) eles não abrangem de forma uniforme a região como é possível ver na parte oeste do batólito. Uma subdivisão mais apurada poderia resolver melhor este embate e assim, no futuro, termos mapas mais atualizados e precisos.

Embora na bibliografia tenham sido descritos poucos minerais compostos de Tório e também não tenha sido destacada a porcentagem deles contido no corpo, é evidente que ainda há mais o que ser descoberto. Tal fato é compreensível de ter ocorrido, uma vez que o corpo apresenta uma área aflorante de aproximadamente $300 \mathrm{~km}^{2}$, e os recorrentes trabalhos tenham tido interesse de uma descrição petrológica e geoquímica de uma forma mais geral abordando vários granitoides da região.

Um estudo mais específico para ETR deve abranger um detalhamento mais apurado a respeito da geoquímica de solo e de uma gamaespectometria terrestre. A malha sugeriada para a aquisição radiométrica são linhas de 100 por 100 metros com leituras a cada 10 metros. Já para a análise geoquímica de solo seriam realizadas picadas de 100 em 100 metros com amostragem de solo a cada 50 metros.

\section{Agradecimentos}

Só se tem um bom trabalho em conjunto, seja pelo conhecimento de outras gerações que perduram através da literatura, ou seja, pelos colaboradores que desfrutam o mesmo espaço-tempo que o nosso como o mestre Alexandre Rocha da Rocha e seu pupilo Henrique Bulhões. Seja pelo apoio de nossa família e nossos amigos. A gratidão é o mínimo que podemos oferecer.

\section{Referências}

KEAREY, Philip; BROOKS, Michael e HILL, Ian. Geofísica de exploração. São Paulo: Oficina de textos, 2009. 391p

CAMPOS, Benedita. PETROGRAFIA, LITOQUÍMICA, QUÍMICA MINERAL E TERMOBAROMETRIA DE ROCHAS CÁLCIO-ALCALINAS DE ALTO $K$ DE TEXTURA PORFIRITICA, EDIACARANAS, NO EXTREMO NE DA PROVÍNCIA BORBOREMA (NE do Brasil). Programa de pós-graduação em geodinâmica e geofísica, Universidade Federal do Rio Grande do Norte, Natal, 2016.

DICKSON B.L., SCOTT K.M. INTERPRETATION OF AERIAL GAMMA-RAY SURVEYS - ADDING THE GEOCHEMICAL FACTORS. AGSO J. Australia Geology \& Geophysics. 17(2):187-200, 1997.

FERNANDES, C.E de M. Fundamentos de prospecção geofísica. Rio de Janeiro: Interciência, 1984.

NASCIMENTO, M.A.L., et al., EDIACARAN TO CAMBRIAN MAGMATIC SUITES IN THE RIO GRANDE DO NORTE DOMAIN, EXTREME NORTHEASTERN BORBOREMA PROVINCE (NE OF BRAZIL): CURRENT KNOWLEDGE, Journal of South American Earth Sciences (2014),

RIBEIRO, Vanessa. INTERPRETAÇÃO DOS DADOS AÉRO GEOFÍSICOS DO LINEAMENTO DE ANOMALIAS MAGNÉTICAS A SUDOESTE DO ESTADO DO MATO GROSSO - SW DO CRÁTON AMAZÔNICO, E SUA RELAÇÃO COM A TECTÔNICA LOCAL. São Paulo. Universidade de São Paulo. 2014

RUDNICK, R.L. AND GAO, S. COMPOSITION OF THE CONTINENTAL CRUST. IN: TREATISE ON 
GEOCHEMISTRY. Holland, H.D. and Turekian, K.K. (Editors), Elsevier, Amsterdam. 3: 1-64, 2004.

SAPUCAIAI N. S.; ARGOLLO R. M.; BARBOSA J. S. F. TEORES DE POTÁSSIO, URÂNIO, TÓRIO E TAXA DE PRODUÇÃO DE CALOR RADIOGÊNICO NO EMBASAMENTO ADJACENTE ÀS BACIAS SEDIMENTARES DE CAMAMU E ALMADA, BAHIA, BRASIL. Rev. Bras. Geof. vol.23 no.4 São Paulo. Dec. 2005.

SBGF (Org.). CPRM libera gratuitamente dados brutos e processados (XYZ) de aerolevantamentos geofísicos. Disponível em: https://www.sbgf.org.br/home/index.php?option=com con tent\&view=article\&id=927:cprm-libera-gratuitamente dados-brutos-e-processados-xyz-de-aerolevantamentosgeofisicos\&catid=14\&ltemid=435 . Acesso em: 17 mai. 2017.

Serviço Geológico do Brasil (CPRM) - COMUNICADO SOBRE DISPONIBILIZAÇÃO DE DADOS DIGITAIS AEROGEOFÍSICOS (MAGNETOMETRIA E GAMAESPECTROMETRIA). Disponível em: http://www.cprm.gov.br/publique/media/sensoriamento $\mathrm{g}$ eofisica/projetos aerogeofisicos/proj aero PB RN PE.p df . Acesso em: 17 mai. 2017.

TEIXEIRA et al. Dados geoquímicos e radiométricos preliminares dos granitos da região de Vila Real, Norte de Portugal. LNEG, Porto, v. 101, Especial I, p.229-332, 2014.

URQUHART, W. E. S. AIRBORNE GAMMA-RAY SPECTROMETRY SURVEYS. GeoExplo, AirborneGeophysical Survey Workshop, 2006.

VASCONCELLOS R.M. Geofísica em levantamentos geológicos no Brasil. Rio de Janeiro: Companhia de Pesquisa e Recursos Minerais, CPRM. 165 p, 1994 